DOI: http://dx.doi.org/10.11606/issn.1984-4867.v27i1p131-152

\title{
Moda, Eventos e Turismo: contribuições do Festival da Moda de Fortaleza para o turismo de eventos na capital cearense
}

\section{Fashion, Events and Tourism: the Fortaleza Fashion Festival's contributions to events tourism in the capital of Ceará.}

\section{Moda, Eventos y Turismo: contribuciones del Festival de Moda de Fortaleza para el turismo de eventos em la capital de Ceará.}

Priscila Medeiros Camelo ${ }^{1}$

Ewerton Reubens Coelho Costa ${ }^{2}$

Luzia Neide Menezes Coriolano ${ }^{3}$

\section{Resumo}

O artigo tem como objetivo analisar a contribuição do Festival da Moda de Fortaleza no desenvolvimento do turismo de eventos local. Trata-se de um estudo de caso, com base na revisão da literatura, pesquisa documental e pesquisa de campo, com levantamento de dados por meio de entrevistas e questionários. Dentre os achados têm-se que a grande maioria dos visitantes são mulheres, vindas da região Norte e Nordeste do Brasil, com faixa etária de 35 a 44 anos e renda mensal de 3 a 5 salários mínimos. Em relação ao comportamento na viagem, infere-se que a maioria utiliza o transporte aéreo para seu deslocamento, permanece de 2 a 3 dias na cidade, participa de atividades turísticas e apresenta gasto médio diário, com transporte, alimentação e hospedagem, de $\mathrm{R} \$ 150,00$ a R $\$ 200,00$. Conclui-se que o Festival da Moda de Fortaleza incentiva a vinda de compradores atacadistas de diversos estados do país para Fortaleza-CE, movimentando a cadeia produtiva da moda e do turismo.

Palavras-chave: Eventos; Turismo de Eventos; Moda; Festival da Moda de Fortaleza.

\section{Abstract}

The article aims to analyze the contribution of the Fortaleza Fashion Festival in the development of the local tourism events. This is a case study, based on literature review, desk research and field research with data collection through interviews and questionnaires. Among the findings are that the vast majority of visitors are women, coming from the North and Northeast of Brazil, aged 35-44 years and monthly income 3 to 5 minimum wages. As for the behavior on the trip, it appears that most use air transport for its displacement remains 2 to 3

\footnotetext{
${ }^{1}$ Mestre em Gestão de Negócios Turístico pela Universidade Estadual do Ceará. Fortaleza, Brasil. E-mail: priscilamedeiros@gmail.com

2 Mestre em Gestão de Negócios Turísticos pela Universidade Estadual do Ceará. Fortaleza, Brasil. Email: ewertonreubens@hotmail.com

${ }^{3}$ Professora do Programa de Pós-Graduação em Geografia e Coordenadora Adjunta do Mestrado Profissional em Gestão de Negócios Turísticos da Universidade Estadual do Ceará (UECE). Fortaleza, Brasil. Email: luzianeidecoriolano@gmail.com.
} 
days in the city, participate in tourist activities and has an average daily spending, with transport, food and lodging, $R \$ 150.00$ to $R \$ 200.00$. It is concluded that the Fortaleza Fashion Festival encourages the coming of wholesale buyers from several states to Fortaleza, moving the production chain of fashion and tourism.

Keywords: Events; Event tourism; Fashion; Fortaleza Fashion Festival.

\section{Resumen}

El artículo tiene como objetivo analizarlacontribucióndel Festival de Moda Fortaleza, eneldesarrollo de los eventos locales de turismo. Este es unestudio de caso, en base a revisión de la literatura, trabajo de documentación e investigación de campo conlarecopilación de datos a través de entrevistas y cuestionarios. Entre lasconclusionesson que lagranmayoría de los visitantes sonmujeres, que vienedel norte y noreste de Brasil, conedades entre 35-44 años y elingreso de 3 a 5 salarios mínimos mensuales. Encuanto al comportamientoenel viaje, parece que lamayoríadel transporte aéreo del uso de sudesplazamientosiguesiendo de 2 a 3 díasenlaciudad, participar enactividades turísticas y tieneun gasto mediodiario, conel transporte, alimentación y alojamiento, $R \$ 150,00$ a $R \$ 200,00$. Se llegó a laconclusión de que el Festival de Moda Fortaleza fomenta lavenida de compradores al por mayor de varios estados a Fortaleza, moviendolacadena de producción de la moda y el turismo.

Palabras clave: Eventos, Eventos del turismo; Moda; Festival Fortaleza de La Moda.

\section{Introdução}

O turismo de eventos e negócios é uma importante atividade para a capital do Ceará pelo efeito multiplicador, pois envolve todos os setores da economia, favorecendo áreas afins e interligadas. O turismo de eventos incentiva o desenvolvimento econômico, sociocultural, contribuindo para a geração de empregos locais, renda e infraestrutura que, por sua vez, beneficia o turista e a cidade receptora. Por isso, desperta cada vez mais a atenção, sobretudo para amenizar a sazonalidade da atividade turística na cidade.

Fortaleza é um núcleo receptor de turismo de sol e praia pelo clima tropical, belezas naturais, vocação ao humor, diversidade gastronômica, além de excelente rede hoteleira. Essas marcas fazem da cidade um dos destinos mais procurados no Brasil ${ }^{4}$. Fortaleza é também um dos

\footnotetext{
${ }^{4}$ A demanda turística via Fortaleza em 2013 foi de 3.141.406, sendo 2.895.646 turistas nacionais e 245.760 internacionais. Sendo $46,8 \%$ das motivações das viagens por passeio, 18,9\% visita a parentes/amigos, $20,9 \%$ negócios/trabalho, 11,5\% congressos/eventos e 1,9\% por outros motivos. (SETUR-CE, 2014).
} 
principais polos de moda do Estado e do País, reúne indústrias têxteis e de confecções, fato que a coloca no cenário nacional como centro dinâmico da moda ${ }^{5}$.

Neste contexto, destaca-se o shopping Maraponga Mart Moda que funciona desde 1990, atraindo clientes de todo o Brasil, pela realização de dois eventos anuais, o Festival da Moda de Fortaleza e Ceará Summer Fashion, que alavancam o mercado de moda local e a cadeia produtiva do turismo. $\mathrm{O}$ texto apresenta resultados referentes à pesquisa realizada sobre $\mathrm{o}$ Festival da Moda de Fortaleza e apresenta o perfil dos compradores atacadistas visitantes, bem como os impactos gerados pelo Festival da Moda de Fortaleza na relação com o turismo.

Assim, tem-se como objetivo analisar a contribuição do Festival da Moda de Fortaleza para o desenvolvimento do turismo de eventos na metrópole. Três perguntas norteiam a pesquisa: Qual a contribuição do Festival da Moda de Fortaleza para o desenvolvimento do turismo de eventos? Qual o perfil do comprador atacadista visitante do evento? Como se dá a relação moda e turismo?

\section{Metodologia}

No intuito de compreender a ligação entre turismo e eventos de moda, especificamente o Festival da Moda de Fortaleza, optou-se por um estudo de caso que permite examinar, com detalhe e profundidade, o contexto que origina o caso (Punch, 1998; Gomez, Flores \& Jimenez, 1996; Yin, 1994).

O estudo de caso não se trata de uma metodologia específica, mas uma forma de organizar dados e informações, preservando a autenticidade do objeto investigado (Goode\&Hatt, 1952, citado em Punch, 1998, p.150). Logo, entende-se que este tipo de estudo busca compreender o caso em seu todo, preservar sua unicidade (Punch, 1998; Gomez, Flores \& Jimenez, 1996, Yin, 1994) e utiliza-se de descrição, por isso faz uso da observação do investigador.

A pesquisa teve suporte nas referências teóricas e procedimentos técnicos de coletas de dados por meio de aplicação de questionários, durante a realização da $35^{\mathrm{a}}$ edição do Festival da Moda de Fortaleza, de 13 a 18 de abril de 2015. O questionário, composto por vinte questões, foi aplicado junto aos compradores atacadistas. O grupo amostral da pesquisa abrange 375

\footnotetext{
${ }^{5}$ No Ceará estão localizadas 97 empresas têxteis e 1.651 empresas fabricantes de artigos confeccionados, sendo 1.592 na área de vestuário, o que no total correspondendo a 5,3\% das empresas da cadeia têxtil brasileira. (ANUÁRIO DA MODA DO CEARÁ, 2011).
} 
(trezentos e setenta e cinco) compradores atacadistas turistas, vindos de diversas partes do país para participar do Festival.

Realiza-se também entrevistas estruturadas, compostas por cinco perguntas, com o idealizador do evento e proprietário do Maraponga Mart Moda, diretor administrativo-financeiro do Maraponga Mart Moda, diretora geral do Festival e entidades ligadas ao turismo de eventos: ABEOC, Fortaleza Convention\&Visitors Bureau e SETUR-CE. Os depoimentos viabilizaram tecer relações entre a teoria e o fenômeno estudado.

\section{Compreendendo e Conceituando Eventos}

Os eventos são significativos para o turismo uma vez que dinamizam fluxos de pessoas com interesses comuns, seja para entretenimento, novos conhecimentos de caráter profissional, pessoal ou negócios. É possível visualizar diversas ocasiões onde os indivíduos se deparam com acontecimentos extraordinários de dimensão pessoal: aniversários, batizados, casamentos e formaturas. No entanto, existem eventos de dimensões diferentes, que envolvem a vida em sociedade: carnavais, shows, festas, feiras e micaretas; assim como eventos de caráter profissional, tais como congressos, colóquios e workshops. Enfim, os eventos estão presentes em quase todos os momentos da vida humana (GIACAGLIA, 2008, p.3).

Essa concepção levou Zanella (2006) a afirmar que evento é uma concentração formal e solene de pessoas ou entidades, realizada em data e local especial, para celebrar acontecimentos importantes, significativos e estabelecer contatos de natureza comercial, cultural, esportiva, social, familiar, religiosa e científica. Enquanto Hall (1992) define eventos como acontecimentos não rotineiros que marcam e identificam realidades sociais. Assim, evento corresponde a um acontecimento que foge da rotina das pessoas e reúne público-alvo específico, em torno de objetivos comuns.

Dinamizadores da economia, os eventos assumem papel importante para o desenvolvimento de lugares, uma vez que proporcionam retorno econômico e social, não se contestando o papel dos eventos para países, regiões ou cidades que buscam destaque no turismo. Britto e Fontes (2002) consideram que no desenvolvimento do turismo várias estratégias ou recursos são utilizados e, entre eles, o de maior resultado é o da organização de eventos. Andrade (2002) acredita que não se deve ignorar o benefício adicional dos eventos, principalmente no item feiras, para criar 
intercâmbios proveitosos entre produção e comércio, com divulgação acentuada de produtos e serviços para compradores.

Seja qual for a natureza os eventos reúnem grupos de pessoas em torno de um mesmo objetivo e muito ajudam a desenvolver o turismo. Atraem pessoas de outras cidades ou regiões, incentivam a economia e enriquecem a vida cultural da cidade onde são realizados. O setor hoteleiro é beneficiado, o que faz com que grande parte dos hotéis tenha instalações especialmente destinadas a esses acontecimentos (CAMPOS, 2000, p.4).

Dessa maneira, acredita-se que os eventos são multiplicadores de negócios e geradores de fluxo, pois motivam a vinda de turistas de diversos lugares. Mobilizando a região onde são realizados, proporcionam melhor aproveitamento dos prestadores de serviços locais, alavancando o consumo de produtos e serviços turísticos, mantendo em movimento a cadeia produtiva do turismo.

Andrade (2002) constata que os eventos favorecem os negócios porque beneficiam diretamente uma diversidade de empresas e atividades, tais como: alimentos e bebida, agência de publicidade, contadores, abastecedores de hotéis, pintores e carpinteiros, transportadores, salões de beleza, relações públicas, decoradores, lavanderias, gráficas e impressoras, autolocadoras, artigos fotográficos, sistema de comunicação, bancos e seguros, artesanato, espetáculos, joalherias, farmácias, postos de abastecimento e outras, sendo mais de 50 segmentos beneficiados. Assim, os eventos dinamizam a economia da cidade anfitriã, movimentam os diversos setores da economia, geram novas oportunidades de emprego para países, regiões ou cidades que buscam destacar-se na atividade turística, incentivam o deslocamento de mais visitantes, tornando-se atividade econômica expressiva para a economia e turismo.

O dimensionamento econômico da indústria de eventos no Brasil, elaborado pela Associação Brasileira de Empresas de Eventos (ABEOC), Serviço Brasileiro de apoio às Micro e Pequenas Empresas (SEBRAE), Confederação Nacional do Comércio de Bens, Serviços e Turismo (CNC), Federação Brasileira de Hospedagem e Alimentação (FBHA) e Fórum do Setor de Eventos (ForEventos), apresenta informações para o desempenho da indústria de eventos no país. Em 2013, registrou-se 590 mil eventos no Brasil, que representaram 4,3\% do PIB do país, geraram 7,5 milhões de empregos diretos, indiretos e terceirizados e contribuíram com 48,7 bilhões de impostos. No Brasil, há 9.445 espaços disponíveis para realização de eventos, com capacidade para 202.171 .787 pessoas - deste número $74,85 \%$ são residentes e $25,15 \%$ não 
residentes. Estima-se o gasto médio diário dos residentes em $\mathrm{R} \$$ 69,22 e dos não residentes em $\mathrm{R} \$ 437,16$. Em relação à distribuição geográfica dos eventos, a pesquisa revela que o Sudeste representa a maior parte do mercado com $52 \%$ dos eventos, seguido pelo Nordeste (20\%), Sul (15\%), Centro-Oeste (9\%) e Norte (4\%) (SEBRAE, 2013).

\section{Turismo de Eventos: um segmento em ascensão em Fortaleza}

O turismo de eventos corresponde ao conjunto de atividades exercidas por pessoas que viajam a fim de participar de eventos como congressos, convenções, feiras, assembleias, simpósios, seminários, reuniões e demais encontros. Em muitos países, esse segmento tem-se desenvolvido significativamente como estratégia inovadora, projetando as potencialidades turísticas e econômicas de municípios e regiões. Ansarah (1999) ressalta que o turismo de eventos é o segmento que leva em consideração o critério relacionado ao objetivo da atividade turística. Praticado com interesse profissional e cultural, em congressos, convenções, simpósios, feiras, encontros culturais, reuniões internacionais, entre outros, é uma das atividades que mais cresce na contemporaneidade.

Para atender as demandas da atividade emergente, espaços foram sendo adaptados ou construídos, tornando-se as bases para o desenvolvimento do turismo de eventos (MATIAS, 2010). A expansão do segmento de eventos estimula hotéis, clubes, bares e restaurantes, que recebiam apenas socialmente, a investirem na construção de espaços exclusivos e equipados para realização de eventos (GIACAGLIA, 2008).

Os eventos proporcionam, a grupos de profissionais de uma mesma área, troca de informações, atualização de tecnologias, debate de novas proposições e lançamento de novos produtos. Além disso, promovem interação de pessoas, contribuem para a geração e o fortalecimento das relações sociais, industriais, culturais e comerciais, gerando fluxos de deslocamento e visitação. Zanella (2006) reafirma a significativa importância dos eventos na área do turismo quando cita que, de acordo com as estatísticas, os turistas que participam de eventos realizam despesa média três vezes maior que à de um turista comum, ou seja, para cada US\$100,00/dia gasto pelo turista de lazer, US\$ 300,00/dia são gastos pelos participantes de congressos, convenções e feiras. A autora estima que cerca de $60 \%$ do fluxo turístico mundial corresponde a viagens de lazer e $40 \%$ deslocamentos de caráter comercial ou viagens de negócios, o que demonstra o papel significativo dos eventos no crescimento e desenvolvimento do turismo. 
Os eventos são um potencial multiplicador turístico, pois normalmente implicam no desembarque de duas pessoas (o congressista e o acompanhante), ajudam a reduzir sensivelmente a sazonalidade, criam uma imagem positiva da cidade-sede, mobilizam o trade turístico e, por consequência, os prestadores de serviços, gerando emprego e renda de imediato e propiciando o ingresso de divisas para o país, estado ou cidade (ANSARAH, 1999, p.77).

O turismo de eventos é uma alternativa ao problema da sazonalidade, considerado um dos maiores entraves para o mercado de turismo, uma vez que corresponde a concentração de fluxos turísticos em determinados períodos do ano, gerando desequilíbrio entre oferta e demanda turística. Andrade (2002) acredita que há uma distinção marcante para os eventos que é a sua capacidade de atração constante, em qualquer época, enquanto o turismo tradicional é mais acentuado nos períodos de férias e de feriados prolongados. Neste caso, os eventos alavancam os negócios turísticos, assumindo posição estratégica entre os destinos com intuito de fomentar,economicamente, os lugares.

Diferente do turismo de sol e praia, o turismo de eventos gera fluxo de turista constante, atraindo turistas que consomem e usufruem, durante os dias de estada na cidade, dos diversos produtos e serviços turísticos, englobando hospedagem, alimentação, transporte e lazer. Desta forma, a realização de eventos é uma estratégia para redução da sazonalidade e proporciona demandas durante o período de baixa estação.

O turismo de eventos exige infraestrutura capaz de dar suporte à realização de eventos. Por isso, acarreta mudanças e melhorias nas localidades que beneficiam tanto o residente como o turista. Campos (2000), Britto e Fontes (2002) citam que para um lugar ser considerado apto para receber turistas nacionais e internacionais, ele precisa investir em transporte, hospedagem, agenciamento e em atividades sociais e turísticas.

Os eventos mobilizam o poder público, ao requerer melhorias da infraestrutura e reorganização da cidade tornando-a preparada para sediá-los, como também o setor privado, que precisa estar preparado para atender o turista-visitante, oferecendo serviços de qualidade para que este sintase satisfeito e retorne.

O mercado de eventos no Brasil surge nos anos 1950, com o lançamento da Feira Nacional da Indústria Têxtil - FENIT, pelo publicitário e empreendedor Caio Alcântara Machado, que realiza o evento, pela primeira vez, em agosto de 1958, reunindo 97 expositores no Pavilhão Internacional do Parque do Ibirapuera. Neste período o Brasil não disponibiliza mão-de-obra qualificada para trabalhar no segmento recorrendo, muitas vezes, a improvisação (MONTES; 
CORIOLANO, 2002). Desde então, o país investe em eventos tendo melhorado consideravelmente os serviços.

A Feira Nacional da Indústria Têxtil - FENIT foi um dos primeiros eventos de moda do Brasil e inovou o mercado de eventos no país. A feira não se mostrou importante apenas para a indústria têxtil brasileira, mas representou, sobretudo, convergência entre as áreas da moda, turismo e eventos. Pode-se afirmar que a FENIT é um marco importante na história dos eventos, em âmbito nacional.

Para disputar com competitividade o mercado de eventos internacionais, o Brasil produziu infraestrutura e investiu na profissionalização e capacitação do setor, tornando-se um mercado competitivo. Surge então, em 1970, o espaço de eventos Anhembi em São Paulo, para realização de eventos. No entanto, a partir de 1970 o Instituto Brasileiro de Turismo (EMBRATUR) começa a investir na construção de espaços semelhantes em outras cidades, favorecendo o crescimento dos eventos no país (CANTON, 2002).

Em Fortaleza, o Centro de Eventos do Ceará (CEC), equipamento da Secretaria do Turismo (SETUR-CE) lançado em 2012, é considerado o mais moderno da América Latina e o segundo maior do Brasil em área útil, com $76 \mathrm{mil} \mathrm{m}^{2}$ e capacidade de comportar até 30.000 pessoas. $\mathrm{O}$ empreendimento recebe feiras, exposições, congressos, workshops, show e outros tipos de eventos de porte nacional e internacional (CEC, 2014).

O turismo de eventos aumenta a receita do local-sede do evento; viabiliza melhoria na infraestrutura da cidade-sede do evento e gera emprego, requerendo um grande número de profissionais para a sua realização. Esses benefícios contribuem para o crescimento e consolidação do segmento de turismo de eventos, possibilitando a movimentação turística em diversos núcleos receptores, demonstrando a força dos eventos na divulgação dos produtos turísticos e promoção de lugares. A atividade chama atenção do setor privado e público que visualizam o segmento como uma importante atividade econômica e social, capaz de proporcionar benefícios para empresas turísticas, cidade promotora e comunidade receptora.

A pesquisa da Organização Mundial do Turismo (OMT, 2013) para o Anuário Estatístico do Turismo 2013, tendo como base o ano 2012, em relação aos motivos de viagens para o Brasil foi constatado que $46,8 \%$ foram por lazer e $25,3 \%$ por negócios, eventos e convenções. E enquanto os turistas de lazer apresentaram US\$ 73,77 de gasto médio por dia no Brasil, os turistas de eventos apresentaram US\$120,25. Cabe ressaltar, ainda, a permanência média no 
país, onde os turistas de lazer permanecem em torno de onze dias e os de eventos treze dias. Outro dado relevante do estudo é que, a cidade de Fortaleza, no ranking de destinos mais visitados no segmento de turismo de eventos, assume a décima posição. Portanto, o segmento do turismo de eventos constitui um importante componente para expansão da atividade turística e da economia local, mantendo um equilíbrio entre a alta e baixa estação.

O Fortaleza Convention\&Visitors Bureau (2014) apresenta pesquisa desenvolvida pelo SEBRAE Nacional, Federação dos ConventionsBureauxs e Consultoria Turística Integrada (CTI), e expõe dados econômicos do turismo de eventos na cidade, no ano de 2011. A pesquisa realizada mostra que 182 eventos foram realizados em Fortaleza, totalizando 16.922.388 participantes, sendo 5.550.543,26 turistas. A cidade teve 38 eventos captados, 58 eventos apoiados e 28 em processo de captação, apenas no ano de referência da pesquisa. $\mathrm{O}$ estudo ainda registrou que entre os segmentos de eventos realizados se destaca os socioculturais, congressos/convenções, feiras e exposições respectivamente. Quanto ao âmbito, a maioria dos eventos foi nacional, concentrando-se nos meses de outubro e novembro. Os dados comprovam que Fortaleza configura-se como cidade propícia à realização de eventos, estando na rota do turismo de eventos nacional, sendo considerado um dos principais destinos no Brasil para o segmento que se revela promissor para desenvolvimento local e turístico. Em entrevista, a diretora comercial do Fortaleza Convention \& Visitors Bureau, mostra que o mercado de eventos em Fortaleza está em expansão e apresenta vantagens competitivas do destino turístico diante dos concorrentes.

O mercado de eventos em Fortaleza está em crescente ascensão. Temos o mais moderno Centro de Eventos - CEC - do Brasil, inaugurado em julho de 2012. O novo CEC foi uma reivindicação do trade turístico de Fortaleza e foi construído e inaugurado pelo Governador Cid Gomes. O FC\&VB ocupa uma posição de destaque na captação de eventos nacionais e internacionais no Brasil e temos um trabalho ao longo dos anos que é referência para o Brasil. São várias as vantagens competitivas de Fortaleza como clima, malha aérea, hotelaria, entretenimento, opções de locais para realização de eventos, diversidade gastronômica, rico artesanato, sem deixar de mencionar a hospitalidade e o bom humor do povo, que contagia a todos que nos visitam (ALVES, 2015, 03 de março).

Fortaleza, desta forma, tem investido na atividade turística e infraestrutura para realização e captação de eventos, concorrendo com destinos consolidados no segmento. Para manter-se competitiva é preciso adotar postura mais arrojada na captação de eventos, como também 
manutenção, reciclagem, atualização e aperfeiçoamento dos eventos já realizados, periodicamente, em Fortaleza.

\section{O Festival da Moda de Fortaleza e o Incentivo ao Turismo de Eventos Local: um} estudo de caso.

O Festival da Moda de Fortaleza (FMF), criado em 1982, fomenta a indústria de confecção da cidade. Pioneiro no setor, o evento incentivou o desenvolvimento da moda no Ceará e a idealização das demais semanas de moda locais. Inicialmente, o evento ocorria na loja de móveis do fundador, o empresário Manoel Holanda, que considerando o sucesso do evento constrói o shopping Maraponga Mart Moda (MMModa), em 1990. A partir de então, o evento passa a ser realizado no próprio estabelecimento (ANUÁRIO DA MODA DO CEARÁ, 2011). Em entrevista, o idealizador e proprietário do Maraponga Mart Moda revisitou o surgimento e a história do Festival. Desde o início, a visão empreendedora o levou a investir no segmento de moda do Ceará. Afirma o empresário do empreendimento:

Iniciamos com o setor de movelaria, ainda na década de 1960. Na década de 1980, procurado pelo governo estadual, nos inserimos na área de confecções com um grande evento de moda. Do evento partimos para o shopping. Na época, em todo o Brasil, se somavam mais de 40 eventos de moda e o FMF se tornou referência para o segmento. O governador Virgílio Távora teve a extraordinária visão de que o Ceará não era propício para agricultura, devido as constantes secas, por essa razão resolveu investir em diversos segmentos da economia nacional, notadamente a indústria de confecções do Ceará teve maior apoio (HOLANDA, 2015, 02 de março).

O Governo do Estado, Secretária do Desenvolvimento, Indústria e Comércio e sessenta confeccionistas cearenses são responsáveis pela realização do Festival da Moda de Fortaleza. Entre os anos 1980 e 1990 os lojistas enfrentavam dificuldades pela economia inflacionada, surgindo então a ideia de promover um evento capaz de reforçar a imagem de Fortaleza como polo de moda.

Afirmam Castilho e Garcia (2001) que o Festival da Moda repercutia como um termômetro da moda brasileira, sendo considerado um dos principais eventos atacadistas da América Latina e um dos grandes colaboradores para a abertura de investimentos têxteis no Nordeste, nos anos 1980. 
O Festival tem abrangência nacional sendo considerado um dos eventos mais importantes do país no setor de atacado, consagrando-se no calendário oficial do Estado e acontecendo anualmente. Para o fundador do evento, o Festival traz "oxigênio" para o setor de confecções e aquece as vendas não apenas do Maraponga Mart Moda, mas de toda a cadeia produtiva da moda. O proprietário expõe a importância do evento para a moda cearense e para a cidade afirmando que:

Durante os primeiros meses do ano, todo o setor de confecção e moda se volta para colocar nas lojas estoque suficiente para abastecer as demandas de datas importantes para o comércio. No FMF, toda essa produção é lançada e apresentada para o mercado atacadista, gerando negócios e, ao mesmo tempo, apresentando o que há de mais recente nas vitrines. O Festival da Moda de Fortaleza é um evento importante para Fortaleza porque atrai, além de compradores, pessoas envolvidas com a cadeia produtiva da moda, desenvolvendo com isso diversos outros segmentos como: restaurantes, bares, hotelaria, taxistas e o comércio de maneira geral (HOLANDA, 2015, 02 de março).

O diretor administrativo-financeiro do Maraponga Mart Moda, afirma que além de movimentar a cadeia produtiva da moda, o evento tem rebatimento na economia do estado, por envolver desde as confecções cearenses até a atividade turística, já que a cidade recebe excursões de compradores de diversas regiões do Brasil.

\footnotetext{
Nos seis dias de evento, a ocupação hoteleira tende a crescer em Fortaleza, pois as vagas do Mart Hotel (hotel interno do shopping) são limitadas e antes mesmo de chegar o FMF, os apartamentos já estão todos reservados e esgotados. Nossa capacidade atual é de 396 hóspedes, divididos em 99 apartamentos. Como a maior parte de nossos clientes são mulheres, hospedamos até quatro compradoras em cada quarto (VARELA, 2015, 26 de fevereiro).
}

Estima-se que durante os dias do evento, o Maraponga Mart Moda recebe cerca de 10 mil compradores atacadistas, sendo $60 \%$ frequentadores de outros estados do Brasil (principalmente das regiões Norte e Nordeste) e $40 \%$ do Ceará. Ademais o evento eleva as vendas dos lojistas do shopping de $10 \%$ a $15 \%$, chegando a uma movimentação de 2 a 2,2 milhões de peças comercializadas somente no período do Festival.

Os produtos apresentados nos desfiles são disponibilizados nas lojas de pronta-entrega do Maraponga Mart Moda, o que garante a movimentação do mercado atacadista de moda e benefícios para fabricantes, corretores e revendedores de moda, que trabalham no mercado como lojistas multimarcas ou atuando em vendas diretas. 
Em 2001 a direção do Shopping constrói, dentro do próprio empreendimento, um espaço para a realização do evento. O Lounge, que é denominado Lounge Lino Villaventura, em homenagem ao estilista paranaense que tem o Ceará como terra natal, apresenta área de $700 \mathrm{~m}^{2}$ e capacidade para receber até seiscentas pessoas, contando com sala de desfile climatizada, passarela, camarim, sala de imprensa e cozinha. A infraestrutura do shopping também é composta por um hotel exclusivo para compradores atacadistas de outros estados, três restaurantes, lanchonete e estacionamento privativo com 200 vagas para carros e 10 para ônibus de excursão, estrutura necessária para atender eficientemente os visitantes do evento e proporcionar conforto e comodidade para os clientes.

O Lounge Lino Villaventura foi criado e pensado pela direção do Shopping para sediar o evento. Giacaglia (2008) afirma que complexos são edificados e dedicados exclusivamente à realização de eventos e que grandes empresas investem na construção e na manutenção de espaços visando à apresentação de espetáculos, atrações musicais ou mesmo eventos empresariais. Desta forma, o Maraponga Mart Moda conta com espaço estruturado e próprio para a realização de eventos e desfiles de moda.

Ademais, o Maraponga Mart Moda está localizado a apenas $4 \mathrm{~km}$ do aeroporto internacional Pinto Martins, 9 km da Rodoviária Engenheiro João Thomé, 9 km do centro de Fortaleza e 15 $\mathrm{km}$ da orla marítima, tendo acesso facilitado por meio de três linhas de ônibus urbanos que partem do Terminal da Parangaba, interligando o Shopping a qualquer ponto da cidade.

A direção geral do Festival destaca que o planejamento e a organização do Evento inicia com seis meses de antecedência, período necessário para definir tema do evento, elaborar campanha, planejar mídia, estratégias e ações, contratar fornecedores, produzir looks dos desfiles, casting de modelos, dentre outras atividades. Sem falar que estão envolvidos na organização do evento diversos profissionais ligados a área da moda, como modelos, camareiras, fotógrafos, jornalistas, stylists, maquiadores, cabeleireiros, seguranças, recepcionistas, passadeiras, montadores, equipe de staff e vendedores.A programação do evento contempla dois horários de desfiles de marcas regionais, sendo um às $8 \mathrm{~h}$, juntamente com café da manhã, e outro às $18 \mathrm{~h}$, com coquetel. A ideia de unir moda e gastronomia partiu da agência Focus, responsável pelo marketing do Shopping e todo planejamento e produção dos eventos. A intenção é oferecer buffet gastronômico para que os revendedores visitantes se deliciem, enquanto conferem os desfiles das marcas. 
Em 2015 o Festival da Moda de Fortaleza chega à 35ª edição com a participação de 300 marcas atacadistas, de diversos segmentos da moda. Todas, durante o Festival, apresentam três peças da coleção de inverno, totalizando 900 looks exibidos durante os desfiles.

$\mathrm{O}$ diretor administrativo-financeiro menciona que $85 \%$ das confecções existentes no Maraponga Mart Moda são genuinamente cearenses, mas há também marcas provenientes de outros estados do Brasil, como São Paulo, Rio de Janeiro, Santa Catarina, Goiânia, Pernambuco, Paraíba, Piauí, Rio Grande do Norte. As marcas de outros estados vislumbram a oportunidade de vir para um novo mercado e um Shopping atacadista consolidado, que consegue atingir públicos consumidores de vários estados.

Os desfiles são segmentados e apresentam caráter comercial e técnico. A cada edição o evento contrata profissionais qualificados para produzir looks condizentes com as tendências nacionais e internacionais. Alguns nomes importantes já assinaram o stylingdo FMF, como Chiara Gadaleta, Antônio Farias, SatorEndo, Marcos Marla e Livia Saboya.

\begin{abstract}
A intenção é informar, deixar os clientes cientes do que é tendência e facilitar as vendas. Por trás dos desfiles há profissionais com expertise em moda, que buscam direcionar as informações, descomplicando a moda. Assim, após os desfiles, os compradores sentem-se mais direcionados e confiantes do que comprar. Muitos deles, já saem da sala de desfile com anotações de lojas a serem visitadas e peças que não podem deixar de comprar, adquirindo produtos de moda de fácil comercialização (MELO, 2015, 15 de março).
\end{abstract}

Afirma Braga (2006) que um desfile precisa criar o caso jornalístico para estar na mídia, considerando que os desfiles correspondem a espetáculos cuja função é seduzir, de forma rápida, compradores e imprensa. Amorim (2007) corrobora com a visão de Braga (2006) ao considerar que os desfiles de moda funcionam como veículo de propaganda, uma vez que a mídia alimenta interesse por eventos, gerando publicidade em torno dos produtos apresentados. Desta forma, para atrair a atenção dos veículos de comunicação e da imprensa, investe-se em celebridades.

A presença de celebridades faz parte da estratégia do Festival da Moda de Fortaleza e tem como objetivo a midiatização, gerar publicidade em torno do Festival e entreter espectadores. É exatamente esse o propósito da contratação de celebridades, afinal agregar o nome de pessoas famosas ao evento faz-se extremamente importante para alcançar destaque na mídia. A escolha das celebridades leva em consideração a atração que estes podem exercem sobre a mídia local e o retorno que geram em termo de publicidade, matérias e divulgação. 
Muitos eventos são realizados simplesmente por dois motivos que, no fundo, refletem apenas só um: fazer aparecer. O primeiro é a formação de opinião, começando-se pelos próprios convidados. O segundo é a esperada repercussão pública dessa ideia/ação promocional/evento: a mídia que pode ser provocada pelo lançamento de marcas ou de produtos, por exemplo (ZOBARAN, 2004, p.33).

Além de participarem dos desfiles, as celebridades convidadas se reúnem com revendedores e visitantes do evento para tirar fotos, conceder entrevistas e autógrafos. Tal fato comprova que o Festival da Moda de Fortaleza não se limita apenas a apresentação de novas coleções das marcas do Maraponga Mart Moda, mas chama atenção da mídia para a principal semana de moda local.

A produção do Festival, orçada em torno de $\mathrm{R} \$ 2.000 .000,00$ (dois milhões de reais), inclui mídia com ações voltadas para o mercado nacional de forma a projetar o Ceará como maior fabricante de confecção da região Nordeste do Brasil. O planejamento de mídia do Evento incluí diversos veículos de comunicação, como televisão, revistas, jornais, outdoors, busdoor, rádio, mídias digitais e mídias aeroportuárias. Para atingir outras regiões do Brasil, o FMF investe emmídia nacional, ampliando a abrangência do evento e atingindo revendedores de moda e lojistas de outros estados e regiões.

O evento dispõe também de serviços de assessoria de imprensa, realizado pela empresa AD2M, que desenvolve o relacionamento do FMF junto aos veículos de comunicação locais e nacionais (jornal, revista, site, rádio e emissoras de televisão). Desta forma, antes mesmo da realização do evento já são veiculadas matérias em veículos especializados - mídia espontânea que agrega valor ao FMF, facilitando a divulgação por todo o país.

A midiatização do evento contribui para divulgação da cidade em outros estados do Brasil e valorização de Fortaleza como polo de moda, o que contribui para o desenvolvimento turístico local, uma vez que os visitantes podem conciliar, durante os dias de estadia, atividades relacionadas ao evento e lazer. Para Melo Neto (2000) é necessário ser criativo ao organizar eventos e todo esforço criativo, na concepção e condução de um evento, deve considerar o que proporciona prazer ao público. Portanto, faz-se necessário pensar ações capazes de seduzir e gerar uma imagem positiva em relação ao evento. Zaina Junior (2005) reforça o pensamento de Melo Neto (2000) ao afirmar que:

A expectativa de algo novo, do encontro com o outro, da participação e integração social traz a excitação das pessoas pelo evento seja esse o 
lançamento de um produto, um show ou uma noite de premiações. O evento é uma ocasião em que as pessoas anseiam por algo especial, que lhes proporcione momentos memoráveis. Independentemente do fator motivador, é essa a expectativa que faz as pessoas investirem seu tempo e recursos para consumir determinado evento (ZAINA JUNIOR, 2005, p. 121).

O acesso ao Festival é aberto e gratuito, mas os desfiles são restritos aos compradores atacadistas que apresentam romaneio de compras acima de $\mathrm{R} \$ 600,00$ (seiscentos reais) nas lojas do Shopping. Os revendedores interessados em conferir os desfiles do FMF, cadastram-se nos balcões de cadastramento distribuídos pelo Shopping, por meio da apresentação de romaneio de compras. Após isso, recebem a pulseira que permite acesso à sala de desfile. Cada desfile apresenta capacidade de receber até seiscentos convidados e o cadastramento viabiliza maior controle do público presente, tornando o evento direcionado e voltado para geração de negócios. Giacaglia (2008) explica que algumas empresas organizam eventos e criam cotas de patrocínio para parceiros que tenham interesse em participar diretamente dele, ganhando visibilidade no mercado e, em particular, entre o público-alvo do evento.

O Festival tem como patrocinadores o SENAC-CE, SEBRAE-CE, FIEC, SENAI e Governo do Estado, que apoiam o evento, tanto financeiramente como institucionalmente, por acreditarem no potencial do Festival e na contribuição que este gera para o polo de moda local. É imprescindível para o evento contar com o apoio de importantes instituições. Ter o nome de grandes entidades atrelado ao Festival da Moda de Fortaleza fortifica e engrandece o evento que já faz parte do calendário da moda local há pelo menos 35 anos.

\subsection{Perfil e comportamento de viagem dos compradores atacadistas do Festival da Moda de Fortaleza}

O perfil dos compradores atacadistas visitantes do Festival da Moda de Fortaleza foi realizado de acordo com as seguintes variáveis: gênero, local de residência, idade e nível de rendimento médio mensal.

No que se refere ao gênero, a amostra total revela que a maioria dos compradores atacadistas são mulheres, sendo $79 \%$ dos visitantes do gênero feminino e $21 \%$ do gênero masculino. No que envolve o local de residência, a maioria dos compradores atacadistas são da região Nordeste e Norte, e dos 375 visitantes pesquisados, 258 residem no Nordeste; 105 no Norte; 9 no Sudeste; 1 no Sul e 2 no Centro-Oeste. Pelo exposto, cerifica-se que o evento tem atração 
geográfica restrita, sendo as regiões Nordeste e Norte os principais polos emissivos de compradores atacadistas para o Festival da Moda de Fortaleza.

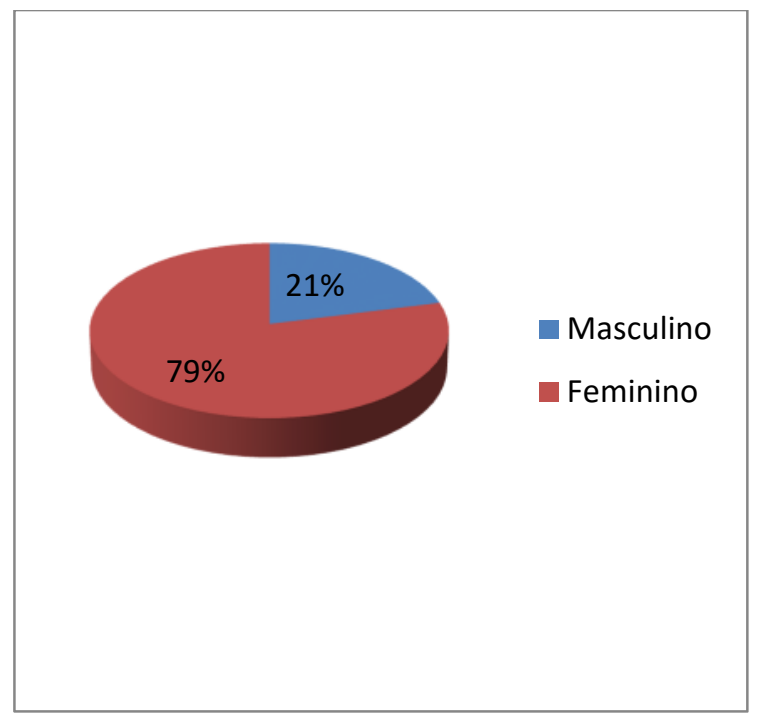

Gráfico 1: Gênero dos Turistas Compradores Fonte: Priscila Camelo (2015)

Relativamente à idade dos compradores atacadistas verifica-se que $0,3 \%$ tem até 18 anos; 2,7\% tem de 18 a 24 anos; $22,7 \% 25$ a 34 anos; $42,1 \%$ de 35 a 44 anos; $21,9 \%$ de 45 a 54 anos; $8,8 \%$ de 55 a 64 anos e 1,6\% mais de 65 anos. Infere-se que a grande maioria dos visitantes são adultos, com idade de 35 a 44 anos.

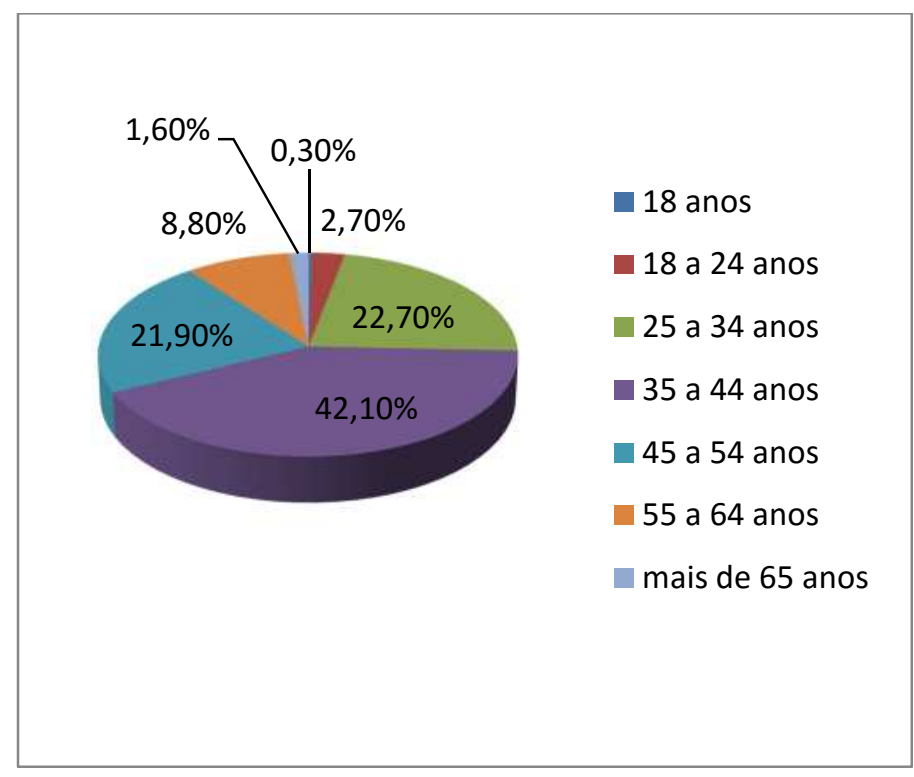

Gráfico 2: Faixa etária dos Turistas Compradores Fonte: Priscila Camelo (2015) 
A renda mensal é um aspecto importante na composição do perfil de um determinado público. Em relação à renda mensal dos compradores atacadistas a amostra revela que 2,4\% recebe até 1 salário mínimo; 29,9\% de 1 até 3 salários mínimos; 34,7\% de 3 até 5 salários mínimos; 26,4\% de 5 até 7 salários mínimos; 4,5\% de 7 até 10 salários mínimos; 1,3\% mais de 10 salários mínimos e $0,8 \%$ não informaram, considerando que o valor do salário mínimo nacional, em 2015, é R \$ 788,00 (setecentos e oitenta e oito reais).

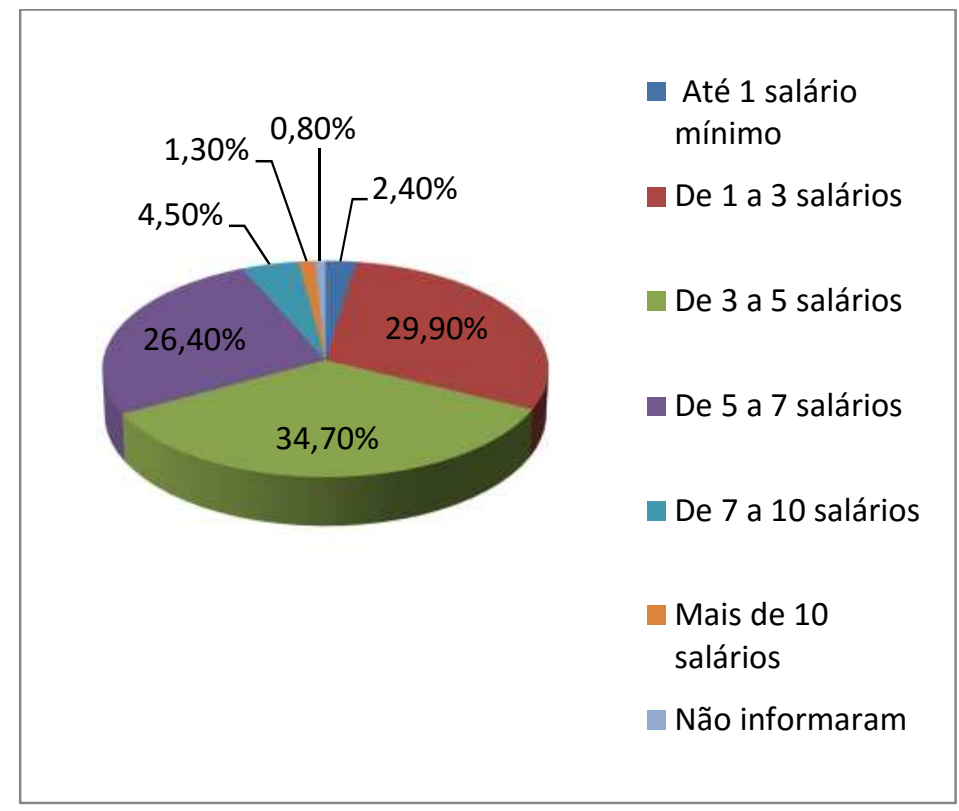

Gráfico 3: renda mensal do dos Turistas Compradores

Fonte: Priscila Camelo (2015)

Quanto ao motivo de viagem, a amostra revela que a motivação de 55,2\% dos visitantes está diretamente ligada a realização do Festival da Moda de Fortaleza; 40,5\% são motivados por negócios; $4 \%$ por passeio/lazer e $0,3 \%$ por outros motivos. No que se refere aos acompanhantes de viagem é possível observar que dentre os 375 entrevistados, $70 \%$ afirma ter vindo com amigos; $45,2 \%$ com o cônjuge; $38,1 \%$ sozinho; $35,6 \%$ em excursão; 5,8\% com os filhos e 5,4\% com outras pessoas. 


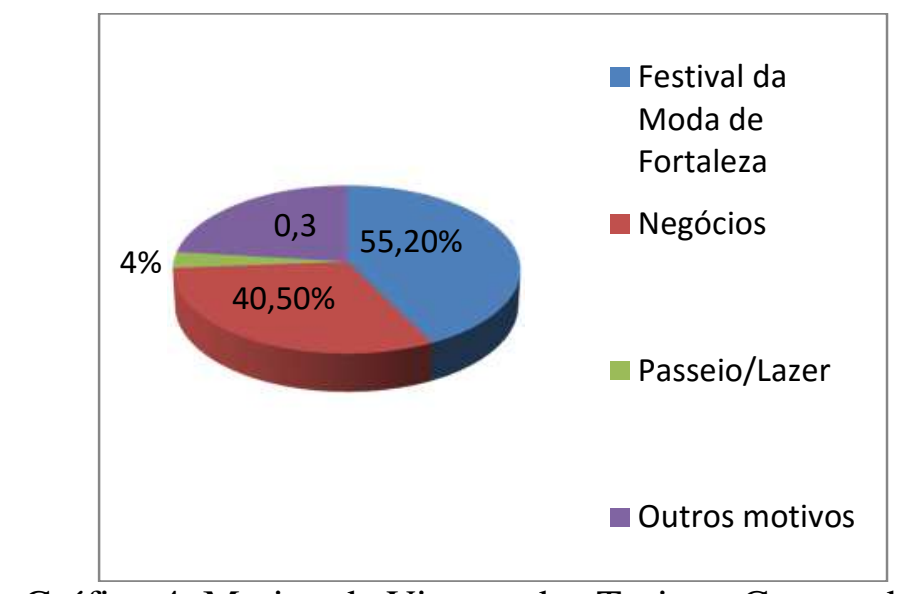

Gráfico 4: Motivo de Viagem dos Turistas Compradores

Fonte: Priscila Camelo (2015)

Em relação aos meios de transportes utilizados identifica-se que 50,1\% dos compradores atacadistas visitantes utilizam o transporte aéreo para seu deslocamento; $24,8 \%$ dos visitantes vieram por meio de ônibus de excursão; $17,1 \%$ de automóvel; $6,9 \%$ ônibus de linha e os demais utilizaram micro-ônibus e van.

Quanto ao tempo de permanência dos compradores atacadistas visitantes em Fortaleza, verificou-se que 14,7\% permanecem 1 dia; $53,3 \%$ dos visitantes permanecem em média de 2 a 3 dias; $28 \%$ encontra-se na cidade de 4 a 5 dias; $2,4 \%$ de 6 a 7 dias e 1,6\% mais de 7 dias.

No que diz respeito ao tipo de hospedagem utilizada, dos 375 entrevistados 140 (37,3\%) optaram por se hospedarem no Mart Hotel, hotel do Maraponga Mart Moda; 137 (36,5\%) optaram por se hospedar nos hotéis da cidade; 44 afirmam não necessitar de hospedagem; 33 $(8,8 \%)$ hospedam-se em pousadas; 17 (4,5\%) em residência de parentes e amigos; $2(0,5 \%)$ em flat e $2(0,5 \%)$ em casa alugada.

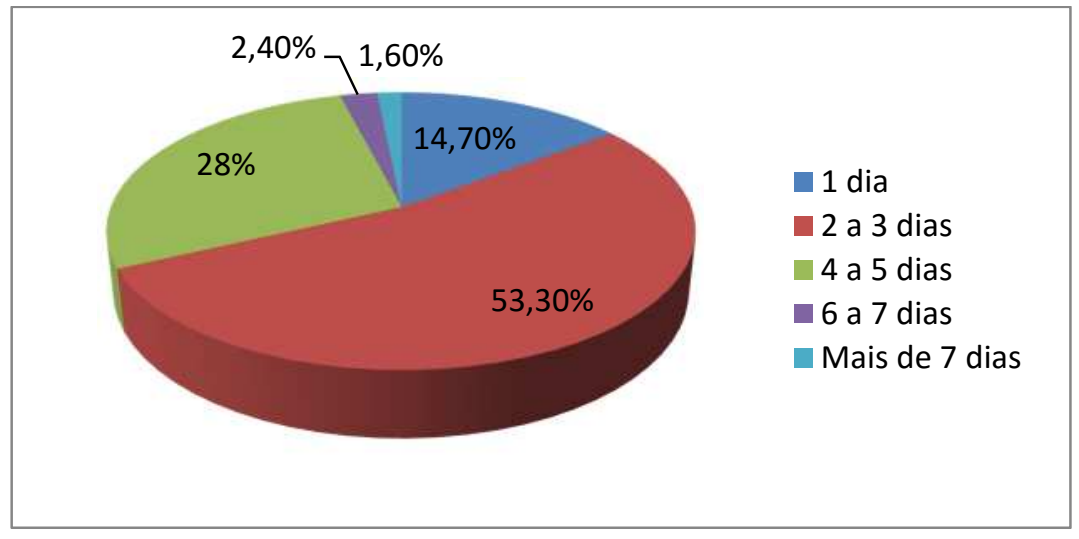

Gráfico 5: Tempo de permanência no destino Fonte: Priscila Camelo (2015) 
No que concerne às atividades turísticas realizadas em Fortaleza, durante o período de estada na cidade, $84,9 \%$ dos inquiridos participaram de outras atividades, além do festival, tais como, passeio na Avenida Beira-Mar (21,7\%); frequentar restaurantes da cidade (18,4\%); show de humor (13,8\%); ir ao shopping (13,5\%); ir à praia (12,8\%); barzinhos $(2,6 \%)$; Beach Park $(1,4 \%)$; cinema $(0,5 \%)$ e teatro $(0,2 \%)$. Pode ser observado também que $15,2 \%$ dos entrevistados afirmam não ter tempo para outra atividade, além das compras feitas no evento.

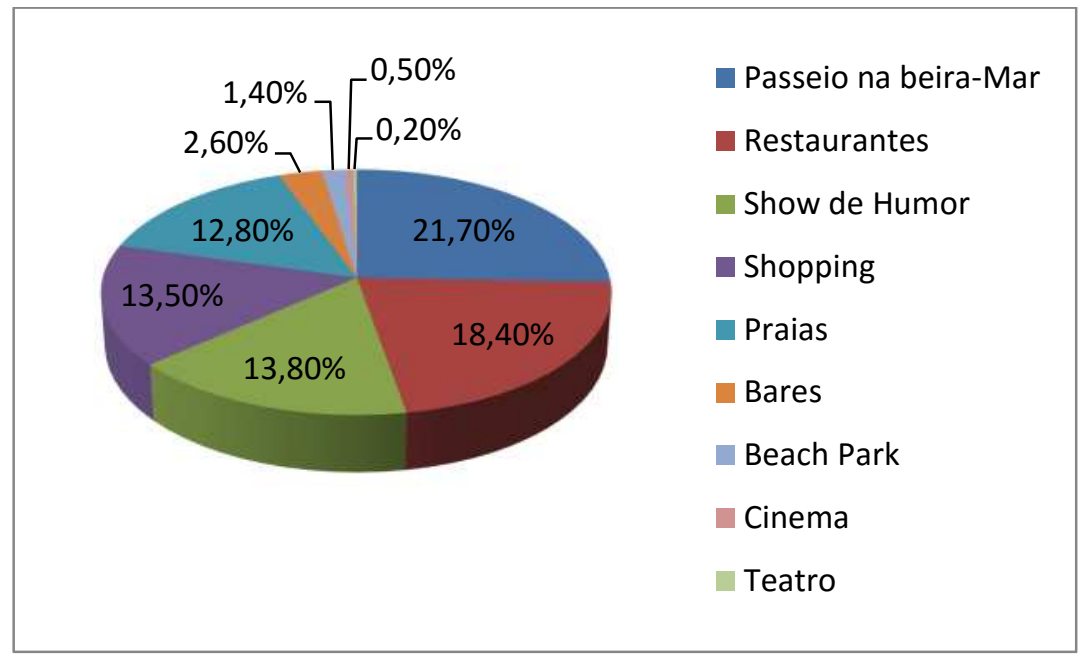

Gráfico 6: Atividades Turísticas realizadas pelos Turistas Compradores Fonte: Priscila Camelo (2015)

No que concerne às despesas com hospedagem, alimentação e transporte os resultados demonstram que $22,1 \%$ dos inquiridos tem um gasto diário médio de $\mathrm{R} \$ 150$ a $\mathrm{R} \$ 200$ reais; $20,8 \%$ afirmam gastar em torno de $\mathrm{R} \$ 50$ a $\mathrm{R} \$ 100$ reais diários; $17,3 \%$ dizem gastar de $\mathrm{R} \$ 200$ a $\mathrm{R} \$ 250$ reais por dia; $11,2 \%$ gastam de $\mathrm{R} \$ 250,00$ a $\mathrm{R} \$ 300,00 ; 9,1 \%$ de $\mathrm{R} \$ 100,00$ a $\mathrm{R} \$$ 150,$00 ; 5,9 \%$ de $\mathrm{R} \$ 300,00$ a $\mathrm{R} \$ 350,00 ; 2,7 \%$ de $\mathrm{R} \$ 350,00$ a $\mathrm{R} \$ 400,00 ; 2,7 \%$ acima de $\mathrm{R} \$$ 400,00 e $8,3 \%$ não informaram.

\section{Conclusão}

O Festival da Moda de Fortaleza dinamiza e mobiliza diversos setores e agentes do mercado, desde compradores atacadistas, empreendedores e prestadores de serviços, movimentando duas cadeias produtivas: a da moda e a do turismo. Infere-se, assim, que o evento é um importante fomentador e divulgador da cidade, gerando recursos para a metrópole, sendo um evento significativo para Fortaleza e relevante para o turismo e moda local. Movimenta a cadeia produtiva da moda e do turismo, contribui para o aumento do fluxo turístico e, 
consequentemente, para o crescimento dos negócios de moda e de turismo. Além disso, a realização do evento coopera para reforçar e disseminar a imagem de Fortaleza como polo de turismo e moda, uma vez que o evento é amplamente divulgado nas mídias de massa. Assim, sendo a atividade turística sazonal, acredita-se que recorrer à realização de eventos de moda, em Fortaleza, é também uma forma de incentivar os fluxos turísticos e de dar destaque ao destino Ceará/Fortaleza.

O Festival da Moda de Fortaleza contempla, unicamente, as marcas do Maraponga Mart Moda, entretanto sabe-se que o universo da moda local envolve grande variedade. Portanto, é interessante que o evento conte com a participação de mais marcas atacadistas locais, enfatizando o mix de segmentos trabalhados na cidade, bem como o artesanato que é um dos grandes diferenciais da moda local e pouco representativo no Festival.

Os resultados obtidos com a pesquisa contribuíram para o conhecimento do perfil dos visitantes do Festival da Moda de Fortaleza, desde a realidade social e econômica dos compradores que frequentam o festival, até o comportamento de viagem destes, onde se detectou que $79 \%$ dos visitantes são do sexo feminino, vindas das regiões Norte e Nordeste do Brasil, com renda mensal de três a cinco salários mínimos, que permanecem de dois a três dias na cidade, apresentando gasto médio diário de $\mathrm{R} \$ 150,00$ (cento e cinquenta reais) a $\mathrm{R} \$ 200,00$ (duzentos reais) e média de valor em compras, no FMF, acima de $\mathrm{R} \$ 10.000,00$ (dez mil reais). Assim, confirma-se mobilidade de fluxos econômicos no destino, uma vez que os participantes, durante os dias de estada na cidade, realizam despesas com hospedagem, alimentação e transporte, além de consumir lazer e entretenimento nas horas de folga, após a realização das compras.

Sendo a atividade turística sazonal, acredita-se que recorrer à realização de eventos de moda, em Fortaleza, é também uma forma de incentivar os fluxos turísticos e de dar destaque ao destino Ceará/Fortaleza. Como sugestão, para aprimorar e inovar o segmento, indica-se: a elaboração de um roteiro turístico integrado à programação do evento, para torna-lo ainda mais atrativo; parcerias entre os diretores do evento e demais empresários da área de turismo, que permitam oferecer maiores possibilidades de atividades de lazer, viabilizando que o visitante do FMF possa criar roteiros de acordo com seus desejos e a criação de um calendário oficial que reúna os eventos da cidade, abrangendo todos os segmentos, inclusive o da moda, com gerenciamento e alimentação permanente. A falta de atividades culturais e turísticas integrando a programação do Evento é uma questão que precisa ser revista. 


\section{Referências}

ALVES, Celina Castro. Depoimento concedido em 03 de março de 2015 a Priscila Medeiros Camelo. ANDRADE, Renato Brenol. Manual de eventos. 2ed. Caxias do Sul: EDUCS, 2002.

ANSARAH, M. G. R. Turismo: segmentação de mercado. Futura, São Paulo. 1999.

ANUÁRIO DA MODA DO CEARÁ. Diário do Nordeste, Fortaleza, v. 2010-2011, 2011.

AMORIM, V. F. de. Desfile de moda: um espetáculo cênico. Florianópolis: Universidade do Estado de Santa Catarina, 2007.

BRAGA, João. Reflexões sobre Moda. Vol. 3. São Paulo: Anhembi Morumbi, 2006.

BRITTO, J; FONTES, N. Estratégias para Eventos: uma ótica do marketing e do turismo. Aleph, São Paulo. 2002.

CAMPOS, L.C.A. Eventos: oportunidades de novos negócios. SENAC Rio de Janeiro, 2000.

CANTON, Antonia Marisa. Eventos: ferramenta de sustentação para o terceiro setor. Roca. São Paulo. 2002.

CASTILHO, Kathia; GARCIA, Carol. Moda Brasil: fragmentos de um vestir tropical. Anhembi Morumbi, São Paulo. 2001.

CENTRO DE EVENTOS DO CEARÁ. O Centro de Eventos do Ceará é o mais moderno e bem equipado da América Latina. Disponível em: <http://centrodeeventos.ce.gov.br/quem-somos/>. Acesso em 20 dez. 2014.

FORTALEZA CONVENTION \& VISITORS BUREAU. História. Disponível em <http://visiteceara.com/historia>. Acesso em 10 nov. 2014.

GIACAGLIA, M. C. Organização de eventos: teoria e prática. São Paulo: Cengage Learning, 2008.

GOMEZ, Gregorio R; FLORES, Javier; JIMÈNEZ, Eduardo (1996). Metodologia de laInvestigacion Cualitativa. Malaga: EdicionesAljibe. 378p

HALL, C. Hallmark Tourist Events. London: Belhaven Press, 1992.

HOLANDA, Manoel Silva. Depoimento concedido em 02 de março de 2015 a Priscila Medeiros Camelo.

MATIAS, M. Organização de eventos: procedimentos e técnicas. 5. ed. Barueri: Manole, 2010.

MELO, Juliana Holanda. Depoimento concedido em 15 de março de 2015 a Priscila Medeiros Camelo.

MELO NETO, Francisco Paulo de. Criatividade em eventos. São Paulo: Contexto, 2000.

MONTES, V. A.; CORIOLANO, L.N. M.T. Turismo de Eventos: promoções e parcerias no Brasil. Revista Turismo em Análise. v. 14, n. 1, p. 40-64, São Paulo. Maio 2003. P. 41-64. Disponível em: <http://www.revistas.usp.br/rta/article/view/63619/66384>. Acesso em: 14 jun. 2014.

ORGANIZAÇÃO MUNDIAL DO TURISMO. Anuário Estatístico de Turismo - 2013. Disponível em: <http://www.dadosefatos.turismo.gov.br/export/sites/default/dadosefatos/anuario/downloads_anuario/ Anuario_Estatistico_de_Turismo_-_2013_-_Ano_base_2012_-_Versao_dez.pdf>. Acesso em: 20 jul. 2014.

PUNCH, Keith. Introduction to Social Research: Quantitative \& Qualitative Approaches. London: SAGE Publications. 1998. 
SEBRAE - Serviço de Apoio a Micro e Pequenas Empresas. II Dimensionamento econômico da indústria de eventos no Brasil. São Paulo, SP: Revista dos Eventos, 2013.

VARELA, Saulo Leite. Depoimento concedido em 26 de fevereiro de 2015 a Priscila Medeiros Camelo. YIN, Robert (1994). Case Study Research: Design and Methods (2a Ed) Thousand Oaks, CA: SAGE Publications.

ZAINA JÚNIOR, Rinaldo. Eventos: a hospitalidade como experiência de consumo pelos sentidos. Revista Hospitalidade: Publicação do Programa de Mestrado em Hospitalidade. São Paulo: Universidade Anhembi Morumbi, [a. II], n.2, p. 113-129, 2005.

ZANELLA, LUIZ CARLOS. Manual de Organização de Eventos:Planejamento e operacionalização. São Paulo: Atlas, 2006.

ZOBARAN, Sérgio. Evento é assim mesmo. Rio de Janeiro, RJ: Senac Rio, 2004.

Recebido em: 10/11/2015 (1 ${ }^{\text {a }}$ versão $)$ 19/04/2016 ( $2^{\text {a }}$ versão)

Aprovado em: 26/04/2016 